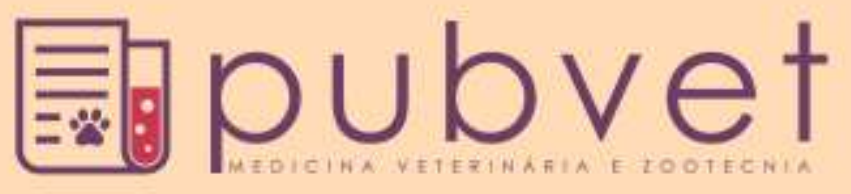

HTTP://DX.DOI.ORG/10.22256/PUBVET.V11N3.290-297

\title{
Construção de um biodigestor caseiro como uma tecnologia acessível a suinocultores da agricultura familiar
}

\author{
Sidney José dos Santos ${ }^{1}$, Elton Lima Santos ${ }^{2 *}$, Ewerton Lima Santos ${ }^{3}$, José Hélio \\ Barbosa $^{4}$, Davi Alves Pereira Junior ${ }^{4}$, Edvânia da Conceição Pontes ${ }^{2}$, Wallace Denisson \\ Santos de Oliveira ${ }^{3}$, Eliel Santana Filho ${ }^{4}$ \\ ${ }^{I}$ Mestre em Zootecnia da Universidade Federal de Alagoas, Centro de Ciências Agrárias. Rio Largo-AL, Brasil. E-mail: \\ sidneysantos54@hotmail.com \\ ${ }^{2}$ Professor (a) da Universidade Federal de Alagoas, Centro de Ciências Agrárias. Rio Largo-AL, Brasil. E-mail: elton.santos@ceca.ufal.br \\ ${ }^{3}$ Estudante de graduação em Agroecologia da Universidade Federal de Alagoas, Centro de Ciências Agrárias. Rio Largo-AL, Brasil. E-mail: \\ ewerton18@ig.com.br \\ ${ }^{4}$ Mestre em Energia da Biomassa da Universidade Federal de Alagoas, Centro de Ciências Agrárias. Rio Largo-AL, Brasil. E-mail: \\ jose.helio2013@uol.com.br \\ *Autor para correspondência
}

\begin{abstract}
RESUMO. A produção e o descarte da biomassa agroindustrial e rural tem sido alvo de muitas pesquisas devido ao seu potencial poluidor bem como também do seu potencial energético. Objetivou-se com esse estudo apresentar uma tecnologia acessível a pequenos produtores de suínos. Utilizou-se as instalações do setor de suinocultura do Centro de Ciências Agrárias da Universidade Federal de Alagoas, onde os animais eram criados em sistema intensivo e alimentados duas vezes ao dia recebendo alimentação balanceada para cada faixa etária. Foram inseridas amostras de dejetos durante 30 dias e depositados em um biodigestor caseiro na proporção 1:1 para cada $\mathrm{kg}$ de dejeto e água. Posteriormente, foi realizado um dia de campo para demonstração da tecnologia a estudantes e pequenos agricultores. Este estudo apresentou a viabilidade da implantação de um biodigestor caseiro como uma alternativa para tratamento dos dejetos, geração de energia alternativa na forma de biogás e o uso auxiliar do biofertilizante, sendo ainda de grande valia o uso ambiental do biodigestor.
\end{abstract}

Palavras chave: biogás, biofertilizante, dejetos, energia, sustentabilidade

\section{Construction of a homemade biodigester as a technology accessible to swine culture of the family farming}

\begin{abstract}
The production and disposal of agroindustrial and rural biomass has been the subject of much research due to its polluting potential as well as its energy potential. The objective of this study was to present a technology accessible to small swine producers. The installations of the Center of Agrarian Sciences of Univeridade Federal de Alagoas, swine sector were used, where the animals were raised in an intensive system and fed twice a day receiving balanced feed for each age group. Samples of waste were inserted for 30 days and deposited in a 1: 1 biodigester for each $\mathrm{kg}$ of waste and water. Subsequently, a field day was held to demonstrate the technology to students and small family farmers. This study presented the feasibility of the implantation of a homemade biodigester as a viable alternative for waste treatment, alternative energy generation in the form of biogas and the auxiliary use of the biofertilizer, being also of great value the environmental use of the biodigester.
\end{abstract}

Key words: Biogas, biofertilizer, waste, energy, sustainability 


\title{
Construcción de un biodigestor casero como una tecnología accesible a los criadores de cerdos de la agricultura familiar
}

\begin{abstract}
RESUMEN: La producción y la eliminación de la biomasa agroindustrial y rural ha sido objeto de considerable investigación debido a su potencial contaminador y también a su potencial energético. El objetivo de este estudio es presentar una tecnología accesible a los pequeños productores de cerdos. Utilizamos las instalaciones del sector de porcinocultura del Centro de Ciencias Agrarias de la Universidad Federal de Alagoas, donde los animales fueron criados en sistema intensivo y alimentados dos veces al día con nutrición equilibrada para cada grupo de edad. Fueron inseridas muestras de desecho durante 30 días y se depositaros en un biodigestor casero en proporción de 1: 1 para cada kg de estiércol y agua. Posteriormente, se realizó un día de campo para demostración de la tecnología a estudiantes y pequeños agricultores. Este estudio demostró la viabilidad de la implementación de un biodigestor casero como una alternativa para el tratamiento de excrementos, generación de energía alternativa en forma de biogás y el uso auxiliar de biofertilizantes, además de ser muy importante desde el punto de vista medio ambiental.
\end{abstract}

Palabras clave: biogás, bio-fertilizantes, residuos, energía, sostenibilidad

\section{Introdução}

Atualmente têm-se discutido bastante a questão energética. Sabe-se que os combustíveis fósseis, além de altamente poluentes, também são considerados recursos não renováveis, e as reservas naturais não devem durar muito tempo. Assim soluções energéticas limpas e renováveis têm sido alvo de muita pesquisa em vários países, e várias destas soluções estão gradualmente sendo implementadas. Uma destas soluções é o biodigestor anaeróbio (Metz, 2013).

A energia provinda da biomassa vem ganhando cada vez mais espaço, dentre as fontes renováveis de energia. No Brasil este fato é ainda mais destacado devido à abundância de resíduos agroindustriais, urbanos e oriundos das criações animais realizadas de forma intensiva. Considerase assim, o Brasil como um país com grande potencial para produção limpa e barata.

No entanto, o desenvolvimento e a difusão de tecnologias energéticas e ambientais limpas e acessíveis ao pequeno produtor rural é demasiadamente difícil; visto a deficiência nos programas institucionais de assistência técnica especializada ou devido à pouca preocupação dos órgãos públicos em relação ao meio ambiente.

Desta forma, os biodigestores são uma alternativa para a produção energética e ambientalmente sustentável ao pequeno suinocultor, tendo em vista a sua eficácia quanto à questão de tratamento de dejetos. A implantação de biodigestores caseiros nas pequenas propriedades rurais pode representar uma medida eficaz no combate à poluição do meio ambiente.
Um biodigestor, digestor ou biorreator pode ser definido como uma câmara de fermentação fechada, onde a biomassa sofre a digestão pelas bactérias anaeróbicas produzindo biogás.

A produção de biogás com o uso de dejetos de animais a partir da biodigestão anaeróbia é visto como uma solução viável para a maioria dos problemas enfrentados com destinação dos resíduos orgânicos no meio rural, pois têm a capacidade de transformar um material inutilizado e incômodo, como os dejetos animais, em uma fonte de energia renovável e limpa (Silva et al., 2015).

Ludke et al. (2007) ressaltam que os dejetos que os animais deixam nas pequenas e médias propriedades são extremamente prejudiciais ao meio ambiente, lançam um gás que provoca o efeito estufa que afeta a camada de ozônio e o solo, através de infiltração no lençol freático, por meio das chuvas que chegam aos igarapés contaminando também as águas.

A construção de um biodigestor pode ser desenvolvida em qualquer propriedade rural, sendo de grande importância para o fortalecimento e a consolidação da agricultura familiar na localidade onde este está inserido.

$\mathrm{O}$ biodigestor, além da energia, contribui ainda para o saneamento das residências, eliminando odores e focos de contaminação dos dejetos orgânicos. $\mathrm{O}$ custo de manutenção é baixo já que é alimentado com material recolhido na propriedade que muitas vezes só serviria como poluente potencial. $\mathrm{O}$ biodigestor pode 
proporcionar ainda outras economias com o uso do biofertilizante, que substitui com vantagens os adubos químicos e inclusive quando aplicado ao solo, melhora significativamente as qualidades físicas, químicas e biológicas deste (Kretzer et al., 2015).

No aspecto da educação ambiental, a implantação de um biodigestor, pode ter vantagens incomensuráveis, visto que pode ser alvo de intensas discussões e reflexões quanto ao uso e preservação do meio ambiente, das prospecções de futuro e como forma de integração da população.

O objetivo deste estudo é a construção e implantação de biodigestor caseiro, para tratamento dos dejetos gerados da suinocultura e utilização do biogás, servindo como modelo de integração entre as a universidade nas suas diversas áreas do conhecimento e a comunidade, propondo com isso uma alternativa para abordagens disciplinares, interdisciplinares e multidisciplinares dentro de um panorama interativo e contextualizado.

\section{Material e Métodos}

O estudo foi executado no setor de suinocultura do Centro de Ciências Agrárias da Universidade Federal de Alagoas, Campus Delza Gitaí - BR 104 Norte, Km 85, Rio Largo - AL. No estudo foi construído um mini biodigestor anaeróbico tipo batelada contínuo de fabricação caseira com capacidade de armazenamento de $200 \mathrm{~L}$, seguindo as recomendações adaptadas de Deganutti et al. (2002).

Como base para a quantidade de dejetos a serem utilizados provenientes do setor de suinocultura foram utilizados quatro suínos, de raças não definidas, com composições sanguíneas de raças como: Large White, Hampshire e Duroc, de diferentes idades. Os animais eram criados em sistema intensivo e alimentados duas vezes ao dia recebendo alimentação balanceada, a base de milho e farelo de soja, de acordo para cada faixa etária.

A biomassa utilizada como combustível foram dejetos de suínos e sobras de ração e água na proporção de 1:1, ou seja, para cada quilograma de dejetos e sobras foi adicionado um litro de água, com uma estimativa de produção de $0,35 \mathrm{~m}^{3}$ de biogás para cada kg de dejeto de suíno, durante 30 dias.
Posteriormente a estabilização do processo biodegradante foi realizada um teste utilizando uma luminária a gás do tipo "lampião" e um fogão doméstico, ambos adaptados e alimentados pelo biogás produzido no biodigestor. Também foi utilizado uma câmara de ar de pneu de caminhão, que serviu como gasômetro de armazenamento do biogás e um termômetro digital com sensor, que serviu como forma de avaliar in loco a temperatura interna do biodigestor. Para a construção do sistema caseiro de biodigestão anaeróbia, foram utilizados materiais de fácil aquisição no mercado local e que também fossem de custos baixos, para o pequeno agricultor familiar como descritos na tabela 1.

Tabela 1. Materiais utilizados na construção do biodigestor caseiro

\begin{tabular}{lcr}
\hline Componente & Unidade & Quantidade \\
\hline Bombona PVC & 100 Litros & 1 \\
Tubulação de unção PVC esgoto & $\emptyset 75 \mathrm{~mm}$ & 1 \\
Tubulação cap PVc esgoto & $\varnothing 75 \mathrm{~mm}$ & 2 \\
Tubulação joelho PVC & $\emptyset 32 \mathrm{~mm}$ & 2 \\
Joelho PVC & $\emptyset 25 \mathrm{~mm}$ & 1 \\
Tubulação em T 90 ${ }^{\circ}$ Soldável & $\emptyset 32 \mathrm{~mm}$ & 1 \\
Tubulação cap soldável & $\emptyset 32 \mathrm{~mm}$ & 1 \\
Registro esfera PVC & $\emptyset 32 \mathrm{~mm}$ & 1 \\
Adaptador soldável rosca & $\emptyset 32 \mathrm{~mm}$ & 1 \\
Flange PVC & $\emptyset 32 \mathrm{~mm}$ & 2 \\
Registro gás alta pressão & $\varnothing 1 / 8 ”$ & 1 \\
Tubulação flange PVC & $\emptyset 25 \mathrm{~mm}$ & 1 \\
Mangueira & $\varnothing 1 / 8 ”(\mathrm{~m})$ & 2 \\
Termômetro digital & und & 1 \\
Câmara de ar de pneu de trator & und & 1 \\
Resina acrílica & Gramas & 500 \\
\hline
\end{tabular}

Para o dimensionamento e a estimativa da viabilidade do biodigestor caseiro a ser construído foi utilizado as recomendações de Oliveira (2004) onde é possível calcular a dimensão do biodigestor utilizando-se da fórmula abaixo descrita, com base na carga diária de matéria orgânica colocada no biodigestor e do tempo de retenção, ou seja, o tempo em que o substrato demora para ser degradado. Utilizou-se como base para o processo completo de biodigestão anaeróbia a taxa de retenção hidráulica de 30 dias.

$$
V B=V C . T R H
$$

Onde:

$\mathrm{VB}=$ Volume do Biodigestor $\left(\mathrm{m}^{3}\right)$;

$\mathrm{VC}=$ Volume de Carga Diária (matéria orgânica + água) ( $\left.\mathrm{m}^{3} / \mathrm{dia}\right)$;

TRH $=$ Tempo de Retenção Hidráulica (dias). 
Já para a estimativa média da produção potencial de biogás, utilizou-se as recomendações de Arruda et al. (2002) onde para cada $1 \mathrm{~m}^{3} \mathrm{de}$ biomassa de dejetos de suínos se produz em média $30 \mathrm{~m}^{3}$ de $\mathrm{CH}_{4}$ (gás metano), levando em conta a qualidade e a quantidade da matéria seca e da quantidade de água. Conforme fórmula abaixo descrita:

Onde:

$$
V=\frac{V C \cdot V M}{V B}
$$

$\mathrm{VB}=$ Volume de biomassa $=1 \mathrm{~m}^{3}$

$\mathrm{VM}=$ Volume de metano produzido para cada $1 \mathrm{~m}^{3} \mathrm{de}$ biomassa $=30 \mathrm{~m}^{3}$

$\mathrm{VC}=$ Volume de carga inicial $=0,1 \mathrm{~m}^{3}$

$\mathrm{V}=$ Volume de biogás produzido.

A quantidade de biogás produzido $\left(3 \mathrm{~m}^{3}\right)$ é suficiente para abastecer uma residência, por aproximadamente 4 horas, dependendo do tipo de queimador utilizado, visto que ele gasta de 0,32 a $0,63 \mathrm{~m}^{3} / \mathrm{h}$, com uma média de $0,45 \mathrm{~m}^{3} / \mathrm{h}$ (Arruda et al., 2002). Para o biogás gerado através dos dejetos dos suínos, de acordo com Abreu et al. (2010) onde, cada suíno produz em média $3,4 \mathrm{~kg}$ de esterco por dia, obtêm-se que: 04 x 3,4 = 13.4 $\mathrm{kg}$ de esterco/dia. Cada $\mathrm{kg}$ de dejeto produz em média $0,43 \mathrm{~m}^{3}$, logo temos que: $13.4 \times 0,35=4,69$ $\mathrm{m}^{3} /$ biogás/dia. A estimativa da necessidade de biogás para uma residência e a conversão destes valores para a aplicação direta do biogás seguiu as orientações de Turdera and Yura (2006) como mostra a tabela 2 .

Tabela 2. Quantidade de biogás necessário para manutenção de alguns equipamentos residências.

\begin{tabular}{lc}
\hline Equipamentos utilizados & Quantidade de Biogás \\
\hline Para a cozinha & $2,10 \mathrm{~m}^{3}$ \\
Para iluminação & $0,63 \mathrm{~m}^{3}$ \\
Para geladeira & $2,20 \mathrm{~m}^{3}$ \\
Para banho quente & $4,00^{3}$ \\
\hline Total de biogás necessário & $8,93 \mathrm{~m}^{3} /$ dia
\end{tabular}

Total de biogás necessário

$8,93 \mathrm{~m}^{3} / \mathrm{dia}$

Fonte: adaptado de Turdera and Yura (2006).

Após a montagem e estabilização do biodigestor, foi realizado um dia de campo com pequenos produtores rurais de alagoas $\mathrm{e}$ estudantes, para a capacitação na construção e manejo do biodigestor, onde foi demostrado aspectos relacionados deste os materiais utilizados, as diversas formas de utilização dos produtos experimentais, como o biogás e o biofertilizante, até informações relacionadas à educação ambiental. O biofertilizante produzido foi armazenado em tambores de 200L e posteriormente utilizado nas pastagens adjacentes utilizadas para bovinos e caprinos e como adubo orgânico em uma pequena horta demonstrativa no próprio setor de Setor de suinocultura da universidade. Posteriormente, com a experiência adquirida dos produtores na capacitação, foi distribuída uma cartilha didática de como construir um biodigestor caseiro, que foi distribuído gratuitamente aos produtores participantes. A cartilha foi confeccionada previamente por estudantes graduando do curso de Zootecnia da Universidade Federal de Alagoas. Ao final do dia de campo foi realizado perguntas diretas e previamente estabelecidas com os participantes, sobre a aceitação a esta nova tecnologia e os conhecimentos adquiridos durante o evento. Os dados provenientes do questionário foram posteriormente tabulados em MS Excel ${ }^{\circledR} \mathrm{e}$ elaboraram-se gráficos. Os dados foram interpretados e avaliados de forma descritiva.

\section{Resultados e Discussão}

De modo geral, o presente estudo demonstrou, de forma simples, a viabilidade de implantação, construção, manutenção e a difusão da tecnologia da utilização do biodigestor caseiro de baixo custo para pequenos agricultores familiares de suínos em Alagoas, visto que a aceitação e a avaliação por parte dos participantes do dia de campo foi considerada positiva, nos aspectos de avaliação de bom e ótimo, para $100 \%$ das pessoas participantes.

Pode-se destacar que somente a construção do biodigestor caseiro e sua permanência no setor de suinocultura do Centro de Ciências Agrárias na Universidade, por si só, já é uma ferramenta rica para o desenvolvimento educacional nas diversas áreas de conhecimento, podendo ser utilizado pelos estudantes dos cursos de graduação ou por estudantes de escolas circunvizinhas do ensino médio e fundamental, além também para o que foi proposto, para pequenos produtores rurais que podem em qualquer momento visitar a universidade e aprender sobre a construção do biodigestor caseiro (Figura 1).

Quando perguntado aos pequenos agricultores familiares participantes do dia de campo sobre biodigestor caseiro sobre quais os principais problemas enfrentados por eles para a efetiva sustentabilidade da produção rural, a falta de assistência técnica e de incentivo governamental foram os fatores mais lembrados por eles, correspondendo a 44 e $28 \%$ respectivamente. 
Entretanto, o aspecto da problemática ambiental também foi lembrado de maneira considerável, onde uma parcela significativa das pessoas citou a preocupação com o meio ambiente, ou seja, o que fazer com o lixo orgânico da residência rural, ou a destinação final dos dejetos animais, e que correspondeu a $20 \%$ das respostas observadas (Figura 2).

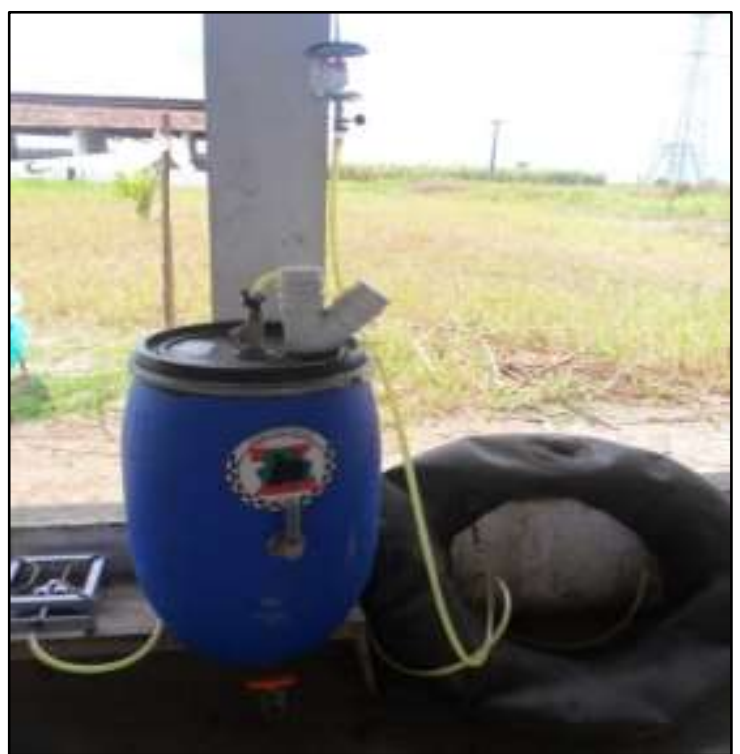

Figura 1. Foto do biodigestor caseiro acoplado ao gasômetro adaptado de uma câmara de ar de pneu de trator e a um fogão doméstico portátil.

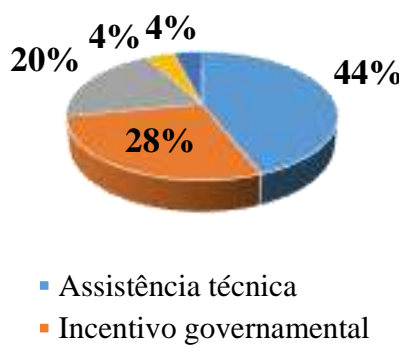

Figura 2. Gráfico com a expressão dos principais problemas demandados pelos agricultores familiares participantes do dia de campo sobre o biodigestor caseiro.

Constata-se assim, que a preocupação com o meio ambiente, que antes era postergada a uma situação inimaginável para o pequeno agricultor familiar, começa a ocupar papel de destaque, visto que grande parte da população rural não possui sistema de tratamento doméstico de esgoto e nem de sistema de tratamento dos dejetos animais produzidos da produção de animais, como os suínos, por exemplo. O que faz com que na maior parte das vezes, os dejetos orgânicos provenientes das criações suinícolas venham a ser despejados diretamente nos corpos água mais próximos, o que consequentemente pode gerar além de problemas ambientais com a eutrofização da água e não nutilização para uso humano, aparecimento de doenças e problemas de saúde pública, o que afeta diretamente e de forma impactante o pequeno agricultor familiar.

Os custos advindos da construção do biodigestor no presente estudo foram relativamente irrisórios já que grande parte dos materiais foram reciclados e ou doados. Fato esse que também pode ser corroborado por grande parte das pequenas propriedades rurais, já que o uso de materiais reciclados ou sem uso atual, podem ser uma alternativa economicamente viável para a construção do biodigestor, já que não precisa ser necessariamente utilizados materiais novos. O tema biogás pode ser visto como uma alternativa sustentável de se adquirir energia com custos reduzidos e menor agressão ao meio ambiente fazendo, assim, não apenas bem a economia, mas também ao meio ambiente (Bezerra, 2013).

Segundo Metz (2013) o biodigestor apresenta vantagens interessantes para a questão ambiental e quando se trata de Brasil, os biodigestores estão principalmente alocados no meio rural, onde apresenta como vantagens a degradação da matéria orgânica dos currais animais, redução dos odores, diminuição de moscas no local, redução de coliformes superior a 99\%, bem como a possibilidade de aproveitamento do biogás produzido como combustível e uso do lodo como fertilizante nas plantações.

Além disso, o uso de biodigestores em propriedades agrícolas contribui para a redução da emissão de gases causadores do efeito estufa, tais como: dióxido de carbono $\left(\mathrm{CO}_{2}\right)$ e metano $\left(\mathrm{CH}_{4}\right)$. Em todo o mundo o uso de biodigestores é bastante difundido, principalmente em países com alta densidade populacional. Da mesma forma, Limmeechokchai and Chawana (2007) citam que na Tailândia, as estimativas da utilização de biodigestores no meio rural podem provocar uma redução significativa redução no consumo de Gás Liquefeito de Petróleo (GLP), no período de 2002 a 2030 , evitando uma emissão de $1.548,80 \mathrm{mil}$ toneladas de $\mathrm{CO}_{2}$. O que corrobora a ideia de que o uso do biodigestor no meio rural tem um apelo ambiental ainda mais enfático comparado a somente a viabilidade econômica da sua implantação.

Concordando com essas afirmativas Segura (2001) afirma que juntamente com a necessidade de substituir o petróleo, surgiu a consciência de que o tratamento de resíduos produzidos pelas 
diferentes atividades urbanas e do campo é de vital importância para a saúde pública e para o combate à poluição das águas. Da mesma forma, Bezerra et al. (2014) afirmam que a cadeia produtiva da suinocultura é mal vista como uma atividade poluidora e que a causa principal da poluição é o lançamento direto do esterco de suínos sem o devido tratamento nos cursos de água, que acarreta desequilíbrios ecológicos e poluição em função da redução do teor de oxigênio dissolvido na água, contaminação das águas potáveis com amônia, nitratos e outros elementos tóxicos. Apesar da importância econômica, social e cultural da suinocultura, a produção tem um potencial poluidor muito grande devido ao grande volume de dejetos gerado por animal e a concentração em pequenas áreas.

Kretzer et al. (2015) estudando as implicações do uso de um biodigestor num ambiente acadêmico, destacaram que as tecnologias apresentadas e as intervenções realizadas contribuíram para o desenvolvimento do potencial dos recursos humanos e da natureza, através das ações práticas, proporcionando maior perspectiva para a juventude, assim como era de fato o objetivo do trabalho, a gestão dos resíduos de forma participativa. Esses mesmo autores ainda relatam que a participação de docentes e acadêmicos permitiu à Universidade socializar e democratizar os conhecimentos de diversos cursos, assim como preparar seus profissionais, não somente com estratégia de ensino, mas complementando a formação com a estratégia do ensino aplicado, mostrando que os objetivos de gestão dos resíduos e a integração entre os envolvidos estão sendo atingidas.

Assim, como no presente estudo o impacto educacional relacionado aos processos de aprendizagem e conhecimento e da prática do uso de um biodigestor num ambiente acadêmico é de extrema relevância e de crescimento progressivo. Considerando desta forma, que as instituições acadêmicas e escolares devem ter como primícias orientadoras o desenvolvimento e o estimulo a métodos de ensino que aproxime a sociedade do meio acadêmico, a construção de biodigestores sendo alocadas como ferramentas educacionais, geraria um ambiente que possa fornecer bases sólidas de ensino através da adoção de temas que possam integrar as diferentes áreas de conhecimento e resultar a partir de então na difusão de saberes e tecnologias que busquem solucionar os problemas sociais, econômicos e ambientais contemporâneo.
Medeiros et al. (2015) relatam ainda o papel de evidência do biodigestor dentro das ações extensionistas, visto o sucesso na gestão dos resíduos sólidos, realçando dessa forma que uma das maiores demandas socioeconômicas ambientais da sociedade contemporânea está relacionado a geração, disposição e gerenciamento dos resíduos sólidos, e que o biodigestor é uma alternativa viável dentro dessas demandas, inclusive como sendo um grande indutor de ações para a elaboração de um plano de gestão de resíduos, no desenvolvimento e teste do biodigestor para a geração de compostos orgânicos para fins agrícolas e extensão comunitária por meio de atividades de educação ambiental junto à comunidade.

No ensino de química, Dantas et al. (2013) relataram que no âmbito acadêmico pode-se notar uma aprendizagem significativa dos alunos participantes, uma vez que os conhecimentos adquiridos foram postos a prova na apresentação do projeto em uma amostra cientifica, sendo o mesmo ainda premiado e também contribuindo no uso do conhecimento em matérias como química, física e biologia, além do uso deste projeto em atividades acadêmicas de outras matérias.

Dessa forma, a alternativa da construção de um biodigestor caseiro e de baixo custo, pode ser uma alternativa interessante para pequenos produtores, principalmente para aqueles que produzem suínos, visto que, os suínos excretam uma quantidade significativa de dejetos diariamente, pois aproveitam apenas uma parte da alimentação ofertada. Assim, o dia de campo oferecido no presente trabalho procurou enfatizar principalmente esse apelo ambiental, já que a viabilidade técnica e a competitividade na produção energética, comparando-se a energia elétrica produzida a partir da rede pública, via hidroelétricas. No entanto vale destacar ainda que existem muitas localidades no meio rural onde a rede de transmissão de energia elétrica do serviço público ainda não está disponível. Sendo dessa forma, ainda mais importante o uso do biodigestor. Segundo Montoro et al. (2013) o depósito inadequado dos dejetos animais pode gerar prejuízos ambientais relacionados à contaminação de solos e da água (lagos e rios), além de problemas sanitários causados pela infiltração desses resíduos nos lençóis freáticos, e do mau odor resultante da emissão dos gases.

Já Oliveira (2004) relata que uma das probabilidades mais duradouras para combater a 
poluição gerada pelos dejetos animais, e ao mesmo tempo agregar valor às propriedades rurais é a tecnologia da digestão anaeróbica realizada através de biodigestores. Além do aspecto da produção energética e do uso do biofertilizante, a viabilidade ou o ganho educacional, da construção de um biodigestor, seja numa escola, numa universidade, ou em qualquer instituição educacional, pode ser considerado um ganho interdisciplinar e multidisciplinar sem mensuração. Muitos são os exemplos e métodos onde foi utilizado o biodigestor como uma ferramenta educacional, para o despertar de uma consciência crítica a respeito de energia, assim também como da preservação do meio ambiente.

\section{Conclusões}

O Presente estudo demonstrou a importância da construção, manutenção e da difusão da tecnologia do uso do biodigestor caseiro para pequenos produtores de suínos em Alagoas. Sendo uma forma sustentável para elucidar os problemas advindos da destinação dos dejetos suínos produzidos em pequenas propriedades. A produção de biogás pode ainda reduzir os custos mensais com outros combustíveis, que pode ser potencializado com a utilização do biofertilizante. Além do que o uso educacional do biodigestor é de grande valia, como uma ferramenta multi e interdisciplinar.

\section{Referências Bibliográficas}

Abreu, Y. V., Oliveira, M. A. G. \& Guerra, S. M. G. 2010. Energia, economia, rotas tecnológicas. textos selecionados. Yolanda Vieira de Abreu.

Arruda, M. H., Amaral, L. P., Pires, O. P. J. \& Barufi, C. R. V. 2002. Dimensionamento de biodigestor para geração de energia alternativa. Revista Científica de Agronomia da Faculdade de Agronomia e Engenharia Florestal, 1, 1-8.

Bezerra, I. L. S. 2013. Produção de gás combustível: Construção de um biodigestor caseiro. IX Congresso de Iniciação Científica do IFRN-Tecnologia e Inovação para o Semiárido. Natal.

Bezerra, K. L. P., Ferreira, A. H. C., Cardoso, E. S., Monteiro, J. M., S., A. I., Júnior, H. A. S. J. \& Silva, R. N. 2014. Uso de biodigestores na suinocultura. Nutritime Revista Eletrônica, 11, 3714-3722.

Dantas, D. F. F., Silva Souza, B., Silva Junior, O. L., Araujo, R. C., Silva, A. S. \& Felicio, D. L.
A. 2013. Biodigestor: uma ferramenta para o ensino de química. XVI ENEQ/X EDUQUI.

Deganutti, R., Palhaci, M. C. J. P. \& Rossi, M. 2002. Biodigestores rurais: modelo indiano, chinês e batelada. Procedings of the 4th Encontro de Energia no Meio Rural. Campinas.

Kretzer, S. G., Nagaoka, A. K., Moreira, T. E., Bauer, F. C. \& Pinto, J. G. C. P. 2015. Educação ambiental em gestão de resíduos e uso de biodigestor em escola pública de Florianópolis. Extensio: Revista Eletrônica de Extensão, 12, 2-13.

Limmeechokchai, B. \& Chawana, S. 2007. Sustainable energy development strategies in the rural Thailand: The case of the improved cooking stove and the small biogas digester. Renewable and Sustainable Energy Reviews, 11, 818-837.

Ludke, J. V., Bertol, T. M., Figueiredo, E. A. P., Woloszyn, N. \& Ajala, L. C. 2007. Avaliação de dietas para sistema orgânico de criação de suínos. Revista Brasileira de Agroecologia, 2, 369-372.

Medeiros, G. A., Caetano, M. M. M., Moraes, F. G., Machado, F. H., Paes, M. X., Amancio, D. T., Ribeiro, A. I., Pinheiro, L. T. \& Ribeiro, L. F. C. 2015. Gestão de resíduos sólidos e biodigestor: abordagem extensionista. Pesquisa em Educação Ambiental, 1, 1-6.

Metz, H. L. 2013. Construção de um biodigestor caseiro para demonstração de produção de biogás e biofertilizante em escolas situadas em meios urbanos. Departamento de Engenharia Rural. Universidade Federal de Lavras, Lavras.

Montoro, S. B., Santos, D. F. L. \& Lucas Júnior, J. 2013. Análise econômica de investimentos que visam à produção de biogás e biofertilizante por meio de iodigestão anaeróbia na bovinocultura de corte. Revista Eletrônica Mestrado em Administração, 1, 2334.

Oliveira, P. A. V. 2004. Produção e aproveitamento do biogás. In: Oliveira, P. A. V. (ed.) Tecnologias para o manejo de resíduos na produção de suínos: manual de boas práticas. EMBRAPA, Concórdia.

Segura, D. S. B. 2001. Educação ambiental na escola pública: da curiosidade ingênua à consciência crítica. Annablume. 
Silva, F. F. M., Bertini, L. M., Alves, L. A., Barbosa, P. T., Moura, L. F. \& Macêdo, C. S. 2015. Implicações e possibilidades para o ensino a partir da construção de biodigestor no IFRN - Campus Apodi. HOLOS, 6, 315-327.

Turdera, M. V. \& Yura, D. 2006. Estudo da viabilidade de um biodigestor no município de dourados. Proceedings of the 6. Encontro de Energia no Meio Rural. Campinas.

\section{Article History:}

Received 14 December2016

Accepted 17 January 2016

Available on line 19 February 2017

License information: This is an open-access article distributed under the terms of the Creative Commons Attribution License 4.0, which permits unrestricted use, distribution, and reproduction in any medium, provided the original work is properly cited. 